\title{
Mercado de trabalho público: percepção de formandos em Odontologia de uma universidade pública
}

\author{
Public labor market: perception of graduating students in Dentistry of a public university \\ Mercado de trabajo público: percepción de formandos en Odontología de una universidad pública
}

Recebido: 29/06/2021 | Revisado: 05/07/2021 | Aceito: 06/07/2021 | Publicado: 16/07/2021

\author{
Débora Cristina Lima de Almeida \\ ORCID: https://orcid.org/0000-0002-5259-0829 \\ Universidade Estadual de Ponta Grossa, Brasil \\ E-mail: debora_lima.almeida@hotmail.com \\ Cristina Berger Fadel \\ ORCID: https://orcid.org/0000-0002-7303-5429 \\ Universidade Estadual de Ponta Grossa, Brasil \\ E-mail: cbfadel@gmail.com \\ Manoelito Ferreira Silva-Junior \\ ORCID: https://orcid.org/0000-0001-8837-5912 \\ Universidade Estadual de Ponta Grossa, Brasil \\ E-mail: manoelito_fsjunior@hotmail.com
}

\begin{abstract}
Resumo
O objetivo do estudo foi analisar motivos de interesse e desinteresse de formandos de Odontologia no mercado público de trabalho, sob o viés das políticas indutoras de (re)orientação da formação acadêmica em saúde. A pesquisa qualitativa, por meio de entrevista individual gravada e roteiro-guia, com amostra definida pelo método de saturação, em universidade pública do Paraná foi realizada em 2017. A análise temática de conteúdo identificou cinco categorias: estabilidade e carreira profissional; experiências vivenciadas durante a formação; processo de trabalho no Sistema Único de Saúde (SUS); perfil do usuário do SUS; retorno social. As experiências vivenciadas durante a formação acadêmica sugerem direcionar o perfil do mercado de trabalho desejado. Ainda, a vivência no processo de trabalho do SUS parece ser capaz de desenvolver uma visão mais crítica e realista sobre a profissão e sobre o setor público, direcionando-o a escolhas profissionais mais assertivas.
\end{abstract}

Palavras-chave: Mercado de trabalho; Recursos humanos em saúde; Odontologia.

\begin{abstract}
The objective of the study was to analyze reasons of interest and lack of interest of dental students in the public labor market, under the bias of policies that induce (re) orientation of academic health education. Qualitative research, through recorded individual interview and guide script, with a sample defined by the saturation method, in a public university in Paraná was carried out in 2017. The thematic content analysis identified five categories: stability and professional career; experiences lived during training; work process in Brazilian Unified Health System (SUS); SUS user profile; social return. The experiences lived during the academic formation suggest to direct the profile of the desired job market. Still, the experience in the SUS work process seems to be able to develop a more critical and realistic view of the profession and the public sector, directing it to more assertive professional choices.
\end{abstract}

Keywords: Job market; Health manpower; Dentistry.

\section{Resumen}

El objetivo del estudio fue analizar los motivos de interés y desinterés de los egresados de Odontología en el mercado laboral público, bajo el sesgo de políticas inductoras (re) orientadoras de la formación académica en salud. En 2017 se llevó a cabo una investigación cualitativa, a través de entrevistas individuales grabadas y guión-guía, con una muestra definida por el método de saturación, en una universidad pública de Paraná. El análisis de contenido temático identificó cinco categorías: estabilidad y carrera profesional; experiencias vividas durante la formación; proceso de trabajo en el Sistema Único de Salud (SUS) de Brasil; Perfil de usuario SUS; retorno social. Las experiencias vividas durante la formación académica sugieren orientar el perfil de mercado laboral deseado. Aún así, la experiencia en el proceso de trabajo del SUS parece ser capaz de desarrollar una visión más crítica y realista de la profesión y el sector público, dirigiéndolos a elecciones profesionales más asertivas.

Palabras clave: Mercado de trabajo; Recursos humanos em salud; Odontología. 


\section{Introdução}

No Brasil, os modelos de atenção à saúde bucal, historicamente excludentes e focalizados, sofreram alterações no início do século XXI, por meio de políticas públicas que passaram a considerar o panorama do cuidado integral, preconizado pelo Sistema Único de Saúde (SUS). Em 2000, a implantação de Equipes de Saúde Bucal na Estratégia de Saúde da Família, e em 2004, a publicação da Política Nacional de Saúde Bucal, reorganizaram e reorientaram o modelo de atenção à saúde bucal no país, atribuindo aos profissionais e ao SUS novos padrões de desempenho. Neste período houve um aumento expressivo do número de vagas ofertadas no setor público, e uma nova concepção sobre o mercado de trabalho para o cirurgião-dentista, o que transformou o Brasil no país com a maior política de saúde bucal do mundo (Pucca-Junior et al., 2015).

No entanto, após a validação desses novos postos de trabalho para cirurgiões-dentistas, principalmente no nível da Atenção Primária à Saúde (APS), e no contexto do trabalho multidisciplinar e em rede, evidenciou-se um descompasso entre a formação profissional e as necessidades de saúde bucal da população brasileira (Faé et al., 2016). Assim, o processo formativo hegemonicamente voltado para o mercado de saúde privado (Souza et al., 2015) revelou ser inadequado para um trabalho na perspectiva da saúde como um produto social e para o cuidado universal, integral e equânime, princípios fundamentais do SUS (Faé et al., 2016).

Sendo competência do SUS orientar a formação de profissionais da área, a ênfase na abordagem integral de saúde, na valorização dos níveis primários de atenção e na integração entre as Instituições de Ensino Superior (IES), serviços de saúde e comunidade (Faé et al., 2016; Pucca-Junior et al., 2015) passa então a ser respondida por políticas no âmbito do Ministério da Educação e do Ministério da Saúde, com atualizações na Lei de Diretrizes e Bases da Educação (LDB) e nas Diretrizes Curriculares Nacionais (DCN) dos cursos de saúde, afim de garantir que Projetos Político Pedagógicos respondam melhor às necessidades de saúde da população. Desta forma, a inserção de estudantes em cenários de práticas do SUS e outros equipamentos sociais, desde o início da formação, é reafirmada nas DCN de todos os cursos de graduação da área da saúde, com implantação de estágios no SUS de forma mais sistemática, inclusive na Odontologia (Faé et al., 2016).

Dentre as políticas estratégicas oriundas desta cooperação técnica entre os Ministérios da Educação e da Saúde, destaca-se, de forma proximal, o Programa Nacional de Reorientação da Formação Profissional em Saúde (Pró-Saúde), o Programa de Educação pelo Trabalho para a Saúde (PET-Saúde), as Residências em Saúde e, de forma distal, o Programa Aprender SUS e a Política Nacional de Educação Permanente em Saúde (Faé et al., 2016).

Enquanto muitos estudos visam conhecer o perfil profissional, o mercado de trabalho odontológico desejado por acadêmicos no Brasil (Barbosa et al., 2013; Cassol et al., 2016; Costa et al., 2012; Ferreira et al., 2013; Gondin, 2002; Matos e Tenório, 2011; Saliba et al., 2012; Sousa et al., 2017; Souza et al., 2015) e sobre a inserção da integração ensino-serviçocomunidade na formação profissional (Costa et al., 2012; Faé et al., 2016; Faé et al., 2017; Silveira e Garcia, 2015), poucos estudos discutem como o aumento do número de vagas no setor público e a inclusão das políticas indutoras de (re)orientação na formação profissional em saúde poderiam interferir na percepção sobre o mercado de trabalho público (Farias-Santos e Noro, 2017). Além disso, não foram encontrados estudos que abordem como as políticas de inclusão social das universidades públicas interferem ou intermediam esta intencionalidade, elemento do presente estudo.

O objetivo deste estudo foi analisar motivos de interesse e desinteresse de formandos de Odontologia no mercado público de trabalho, sob o viés das políticas indutoras de (re)orientação da formação acadêmica em saúde. 


\section{Metodologia}

\subsection{Desenho do estudo e aspectos éticos}

Estudo qualitativo realizado com formandos do curso de Odontologia de uma universidade pública do Paraná, em 2017 (n=57). O estudo foi aprovado pelo Comitê de Ética em Pesquisa da Universidade Estadual de Ponta Grossa sob o protocolo de número CAAE: 79531717.2.0000.0105.

\subsection{Local do estudo}

O referido curso de Odontologia tem entrada única anual de 60 alunos e o atual Projeto Político-Pedagógico do curso (PPC) está em vigência desde 2016. No entanto, o estudo foi realizado com uma turma do PPC anterior, com implantação no ano de 2005, onde a disciplina de Saúde Coletiva II (teórica) e a disciplina de Saúde Coletiva III (estágio na APS) estavam vinculadas ao quarto ano de integralização curricular. Desde o ano de 2008, o curso instituiu o estágio obrigatório no SUS, considerando como cenário a rede pública de saúde bucal do município no âmbito da Atenção Primária e da Estratégia Saúde da Família. Visando então oportunizar a vivência do processo de trabalho de uma equipe de saúde da família, além do conhecimento sobre o território vivo em atividades preventivas e de promoção de saúde em diferentes espaços sociais (unidades de saúde, escolas, centros municipais de educação infantis, etc.), o mote da disciplina de estágio não se encontra em ações curativistas ou em procedimentos curativos reabilitadores.

Em 2007, a universidade adotou o sistema de ações afirmativas com reservas de vaga de cotas sociais por renda e raça/cor. Além disso, tradicionalmente o curso de Odontologia em questão apresenta um eixo forte de integração com osserviços de saúde, por meio de disciplinas obrigatórias com atendimentos clínicos extramurais, sendo a referida IES a única responsável pelo atendimento odontológico de usuários de dois distritos rurais do município. Além disso, o curso integrou as últimas edições dos programas Pro-Saúde e PET-Saúde, com participação nas propostas intituladas PET-Saúde/Vigilância, PET-Saúde/Redes, PET-Saúde/GraduaSUS.

Durante o ano de 2017, durante a vigência e como desdobramento do PET-Saúde/GraduaSUS, a instituição organizou uma disciplina integradora optativa com caráter multiprofissional, fomentando a participação de alunos dos diversos cursos de saúde e o desenvolvimento projetos de intervenção multidisciplinares na APS do município. Como campo de atuação em saúde coletiva ao acadêmico de Odontologia, a instituição ainda conta com programa de Residência Uniprofissional em Cirurgia e Traumatologia Buco-Maxilo-Facial e Residência Multiprofissional em Saúde nas áreas de Saúde do Idoso, Intensivismo e Neonatologia.

\subsection{Amostra}

A amostra foi determinada pelo método de saturação, ou seja, quando começa haver a repetição dos dados coletados entre os indivíduos participantes (Fontanella et al., 2008). Os critérios de inclusão foram: ser concluinte do curso de Odontologia, estar devidamente matriculado no segundo semestre letivo do curso (2017) e concordar em participar livremente da pesquisa, por meio da assinatura de Termo de Consentimento Livre e Esclarecido.

\subsection{Coleta de dados}

Os dados foram coletados na última semana letiva do curso, na própria instituição, por meio de entrevista individual gravada e previamente agenda em sala reservada. Dois pesquisadores treinados utilizaram um roteiro-guia inédito que versava sobre a perspectiva pessoal para inserção no mercado de trabalho e sobre o interesse na atuação no serviço público. Para o presente estudo foram extraídas características demográficas básicas, dados referentes ao ingresso e atuação no curso de Odontologia e informações referentes às seguintes questões-chave: "Relate qual sua expectativa para inserção no mercado de 
trabalho imediatamente após a conclusão do seu curso de graduação" e "Como foi a experiência nas disciplinas de Saúde Coletiva? Escolheria trabalhar no serviço público? Por quê?".

Previamente à coleta dos dados, houve treinamento entre os entrevistadores, de modo que as entrevistas fossem conduzidas de maneira imparcial e que buscassem extrair o aprofundamento necessário através dos contextos e sentidos atribuídos pelos entrevistadosaos seus motivos de interesse e desinteresse no mercado de trabalho público. Além disso, vale ressaltar que os entrevistadores não possuíam contato direto ou vínculo com os entrevistados.

As entrevistas duraram em média 10 minutos e foram registradas utilizando-se um gravador de voz digital (Sony ICDPX312, Estados Unidos), sendo posteriomentetranscritas na íntegra por um único pesquisador, com o auxílio de um software de transcrição (Voicemeeter, Estados Unidos).

\subsection{Análise dos dados}

A análise temática de conteúdo seguiu o método proposto por Bardin (2016), através de um conjunto de técnicas interpretativas que visam descrever um sistema complexo de significados. A partir da leitura flutuante de todo o material empírico transcrito, sem se ater às questões individuais contidas no roteiro-guia, houve a decodificação dos sentidos presentes nos discursos referentes ao mercado de trabalho público.

Os dados foram analisados por dois pesquisadores, inicialmente de forma independente, e depois de forma conjunta, para assim, ocorrer a definição das categorias de análise. Em caso de discrepância, recorreu-se à um terceiro pesquisador, com ampla experiência em análise qualitativa, o qual estabeleceu consenso no processo de categorização das respostas.

Os resultados foram apresentados com trechos dos discursos por meio de citação direta, de forma codificada, onde o entrevistado é identificado como Egresso (E) e um número contínuo.

\section{Resultados e Discussão}

Houve participação de 24 formandos do curso de Odontologia da Universidade Estadual de Ponta Grossa (UEPG), sendo a maioria mulheres, média etária de 22 anos, ingressantes por vestibular tradicional e por sistema de cotas. Todos cursaram as disciplinas obrigatórias de Saúde Coletiva, e quatro participaram de políticas indutoras para discentes: PET-Saúde ou disciplina optativa integradora multidisciplinar (Tabela 1). 
Tabela 1. Características da amostra. Ponta Grossa-PR, Brasil, 2017.

\begin{tabular}{|c|c|c|c|c|c|}
\hline $\begin{array}{l}\text { Participante } \\
\text { (Código) }\end{array}$ & Sexo* & $\begin{array}{l}\text { Idade } \\
\text { (anos) }\end{array}$ & Forma de ingresso & Ingresso por cotas & $\begin{array}{l}\text { Política Indutora } \\
\text { Específica }\end{array}$ \\
\hline 1 & $\mathrm{~F}$ & 26 & Vestibular & Sim & Não \\
\hline 2 & $\mathrm{~F}$ & 22 & Avaliação Seriada & Não & Não \\
\hline 3 & $\mathrm{~F}$ & 22 & Vestibular & Sim & Não \\
\hline 4 & $\mathrm{~F}$ & 23 & Vestibular & Sim & Não \\
\hline 5 & $\mathrm{~F}$ & 23 & Vestibular & Sim & Não \\
\hline \multirow[t]{2}{*}{6} & & & & Não & Disciplina \\
\hline & $\mathrm{F}$ & 24 & Vestibular & & Multiprofissional \\
\hline 7 & M & 26 & Vestibular & Sim & Não \\
\hline 8 & M & 23 & Vestibular & Sim & Não \\
\hline 9 & M & 21 & Vestibular & Não & Não \\
\hline 10 & $\mathrm{~F}$ & 23 & Vestibular & Sim & Não \\
\hline 11 & $\mathrm{~F}$ & 22 & Avaliação Seriada & Não & Não \\
\hline 12 & M & 22 & Vestibular & Sim & Não \\
\hline 13 & $\mathrm{~F}$ & 22 & Vestibular & Não & Não \\
\hline 14 & $\mathrm{~F}$ & 24 & Vestibular & Não & Não \\
\hline 15 & $\mathrm{~F}$ & 24 & Vestibular & Não & Não \\
\hline 16 & $\mathrm{~F}$ & 22 & Vestibular & Sim & PET-Saúde \\
\hline 17 & $\mathrm{~F}$ & 22 & Vestibular & Não & Não \\
\hline 18 & M & 23 & Vestibular & Sim & PET-Saúde \\
\hline 19 & $\mathrm{~F}$ & 22 & Avaliação Seriada & Não & Não \\
\hline 20 & $\mathrm{~F}$ & 23 & Vestibular & Não & Não \\
\hline 21 & $\mathrm{~F}$ & 32 & Transferência Interistintucional & Não & Não \\
\hline 22 & M & 26 & Vestibular & Sim & PET-Saúde \\
\hline 23 & $\mathrm{~F}$ & 21 & Avaliação Seriada & Não & Não \\
\hline 24 & $\mathrm{~F}$ & 22 & Transferência Interistintucional & Não & Não \\
\hline
\end{tabular}

*M: Masculino e F: Feminino. Fonte: Autores.

Verificou-se o desejo de grande número de formandos pela inserção no mercado de trabalho público, o que pode indicar maior entendimento sobre as mudanças no mercado de trabalho odontológico e o êxito das medidas adotadas pelas DCN, mudanças curriculares e políticas indutoras estratégicas da formação em saúde (Barbosa et al., 2013; Cassol et al., 2016; Ferreira et al., 2013; Finkler et al., 2014; Souza et al., 2015).

Os indivíduos que apresentaram interesse pelo serviço público apontaram o exército, os hospitais e as unidades de saúde como locais passíveis de atuação. A presença de interesse em outros locais do serviço público odontológico, além de unidades de saúde, pode demostrar a percepção de ampliação de mercado que a Odontologia tem conseguido nas últimas décadas, principalmente na atenção hospitalar (Gonçalves et al., 2014).

Após a análise temática, foi possível identificar entre motivos de interesse ou desinteresse no mercado público odontológico, as seguintes categorias: estabilidade e carreira profissional, experiências vivenciadas, processo de trabalho, perfil do usuário e aspecto social.

\section{Estabilidade e carreira profissional}

As percepções angariadas mostraram que as inseguranças sobre o futuro profissional e o mercado de trabalho, típicas de acadêmicos formandos, colocam o setor público como oportunidade adequada para o emprego em saúde entre recémformados, ao afirmarem que teriam uma "garantia de trabalho (...) [na] condição de recém-formado" (E07) ou pela "insegurança de abrir o próprio consultório e não dar certo" (E10). Além disso, afirmaram que o SUS seria uma boa estratégia inicial: "para o começo [de carreira]" (E05); “talvez por um começo eu cairia lá [serviço público], fazendo um concurso e passado eu iria, mas não é meu foco" '(E20). 
A percepção sobre a inserção imediata ou a curto prazo no serviço público no inicio da carreira, pode ser considerada uma forma de ascensão profissional (Sousa et al., 2017). No entanto, esta perspetiva inicial torna-se contraditória à necessidade do serviço público, principalmente na APS, onde a resolutividade depende da fixação de profissionais, visando à longitudinalidade do cuidado (Kessler et al., 2018).

Além disso, a insegurança sobre habilidades técnicas adquiridas durante a formação acadêmica fazem os formandos enxergarem no serviço público um espaço profícuo para a (re)construção de saberes, quando afirmam que é um serviço "bom pra pegar mão" (E04). No entanto, o serviço público, enquanto organização ligada ao aparato do Estado, não pode ser visto apenas como um campo de aprendizagem e amadurecimento profissional. Neste sentido, a implantação e expansão dos programas de Residências Uni e Multiprofissionais em Saúde talvez impacte na redução dessa insegurança inicial do recémformado, pois oferece maior autonomia aos profissionais em um processo misto de educação continuada, educação permanente e educação em serviço (Peixoto et al., 2013).

Os programas de residência agregam novas expressões de formação profissional relacionadas na união entre ensinoserviço-comunidade, em uma perspectiva de benefício para os atores envolvidos (Pucca-Junior et al., 2015), devendo então os processos educativos em saúde pautarem-se em princípios metodológicos cujas implementações possibilitem a motivação profissional e a consequente transformação e fortalecimento do processo de trabalho e das práticas profissionais.

Uma parcela considerável de formandos expôs garantia de interesse no mercado público, sendo o aspecto financeiro frequentemente citado: "um lugar onde tem um salário fixo" (E09). Essa segurança de estabilidade financeira propriamente dita ou as vantagens trabalhistas envolvidas nesse processo têm sido demonstradas como maiores motivadores na busca de emprego no setor público, mesmo entre universitários da rede educacional privada (Sousa et al., 2017). Esse aspecto ganha reforço frente ao fato do setor público brasileiro, representado pelo SUS, atualmente configurar-se como o maior empregador de mão de obra odontológica (Ferreira et al., 2013).

Estudos confirmam o interesse de acadêmicos fomandos na garantia salarial ofertada pelo serviço público, visando uma maneira de honrar suas despesas fixas, sem deixar o trabalho concomitante no serviço privado (Costa et al., 2012; CASSOL et al., 2016). Apesar de um estudo questionar a falta de responsabilidade no processo de trabalho entre profissionais que julgam o salário no serviço público como baixo e apenas complemento de remuneração, seus autores verificaram também que o crescimento da oferta de trabalho na rede pública tem levado os cirurgiões-dentistas admitidos a se identificarem com o emprego, e assim, o valorizarem (Reibnitz Júnior et al., 2009).

A estabilidade do setor público, apesar de parecer para alguns como aspectopositivo, foi vista negativamente por alguns formandos, como mostra o discurso: "(...) se eu fosse para a saúde pública iria ficar sempre na mesma tecla ali, não ia conseguir crescer [profissionalmente]" (E22). Neste contexto, talvez a baixa governabilidade e a estabilidade do serviço público possam ser interpretadas por alguns indivíduos como estagnação profissional, apesar de existirem grande parte dos serviços públicos um Plano de Cargo, Carreira e Salários no intuito de fixação e motivação dos trabalhadores de saúde (Mendes et al., 2018).

No mesmo sentido, o conceito de sucesso profissional na ótica odontológica parece ainda estar associado a uma lógica de mercado, baseado na perspectiva de maior autonomia, em plano de carreira com metas e objetivos individuais mais claros e perceptíveis, e na ideia de progressão salarial acelerada. Apesar de ensaios jurídicos buscarem a reorganização das carreiras de assistência pública à saúde no Brasil, via de regra, a capacitação para o cuidado mais complexo, a atuação frente às demandas populacionais exacerbadas, dentre outros, não são aspectos considerados.

Sendo assim, o ideário da realização profissional parece estar associado ao mercado privado, como exposto nas seguintes falas: "expectativa (...) [de] frustrar trabalhando na unidade de saúde é bem grande”(E08) e como "um serviço muito ruim (...), um trabalho que você não vai ter retorno, (...) não vai ter resultado (...), não fala (...) nossa meu trabalho vale 
a pena!" (E19) e o "sucesso profissional como cirurgião-dentista, (...) nada iria agregar mais (...) que uma atuação mais clínica“ (E22).

Os resultados do presente estudo corroboram os achados daprocura histórica de egressos dos cursos de Odontologia pelo mercado privado (Souza et al., 2015), principalmente pela formação voltada para o exercício liberal da profissão (Morita et al., 2010), embasado ainda nos pressupostos do modelo biomédico (Kessler et al., 2018). Nesse sentido, o interesse pelo serviço público tem um caráter secundário, menos importante e com menor condição social (Finkler et al., 2014). Diante deste referencial e considerando principalmente o cenário nacional, é possível indagar se a escolha atual pelo curso de Odontologia é tomada com racionalidade e conhecimento da realidade da profissão (Cassol et al., 2016; Souza et al., 2015) ou fundamentada na visão utópica dos tempos áureos da profissão (Ferreira et al., 2013).

Estudos têm verificado que o interesse no serviço particular vem diminuindo entre os acadêmicos da saúde ao longo do período de sua formação, seja para concluintes de instituições públicas ou particulares (Barbosa et al., 2013; Cassol et al., 2016; Souza et al., 2015), o que demonstra uma visão mais realista sobre o mercado de trabalho (Ferreira et al., 2013; Souza et al., 2015) e uma mudança gradativa nas escolhas das práticas odontológicas para o setor público (Souza et al., 2015). No entanto, não se sabe ao certo se o fato deriva das perspectivas profissionais idealizadas pelos acadêmicos, do mercado dinâmico que não absorve os profissionais na iniciativa privada (Ferreira et al., 2013), da ampliação da cobertura dos serviços públicos odontológicos (Pucca-Junior et al., 2015), das políticas indutoras de articulação ensino-serviço-comunidade (Fae et al., 2016) ou da junção de todos esses aspectos.

Neste sentido, entender como a formação acadêmica pode interferir nas escolhas profissionais futuras pode reduzir conflitos internos sofridos pelo cirurgião-dentista após a sua inserção no mercado de trabalho, os quais podem culminar no abandono da profissão (Ferreira et al., 2013).

\section{Experiências vivenciadas durante a formação}

Experiências exitosas vivenciadas ao longo da vida acadêmica apareceram como aspectos importantes do interesse pelo serviço público, seja por experiência individuais, como nos discursos: "o que ajudou mais a ter mais vontade de fazer [concurso público] (...) [foi que] (...) meu tio (...) é dentista, ele também atende na unidade da saúde, sempre (...) eu ia com ele" (E12), seja por experiências diretamente ligadas à formação acadêmica, principalmente nos estágios curriculares obrigatórios, como nas falas: "a Saúde Coletiva [disciplinas] me deu uma perspectiva completamente diferente, eu nunca tinha entrado em uma unidade [de saúde] (...). Comecei a ver, conhecer e a ser usuária também" (E06); "Gostei do posto de saúde, (...) o SUS tá funcionando aqui, então achei bem legal" (E13). Também existiu correlação de interesse com a vivência na disciplina integradora: "faço uma disciplina multiprofissional que vai na unidade de saúde, gostei muito de fazer" (E06).

Esses discursos confirmam que a identidade profissional dos indivíduos sofre influência da percepção sobre mercado de trabalho, vivências pessoais e da formação que recebem, seja antes ou após o ingresso na graduação (Gondin, 2002), e têm correspondido às Diretrizes Curriculares Nacionais, que visam uma formação humanista, crítica, reflexiva e voltada para a realidade de saúde da população (Fae et al., 2016). Os discursos reforçam a premissa de que a vivência acadêmica na rotina dos serviços de saúde pública durante o estágio extramuros, ou por meio de políticas indutoras estratégicas, como as disciplinas integradoras multidisciplinares na universidade, foram importantes para o conhecimento da rotina e do processo de trabalho do serviço público.

O presente estudo mostrou que a inserção e o conhecimento do serviço público foram determinantes tanto para o interesse como para o desinteresse nesse mercado de trabalho, como também apresentado nos discursos das demais categorias de análise. Sendo assim, as instituições de ensino devem fomentar a orientação profissional, entendida como uma dificuldade para o recém-formado (Saliba et al., 2012), e favorecer a formação além do exercício liberal da profissão (Morita et al., 2010), 
com vistas à atuação múltipla no mercado de trabalho, considerando, em especial, as peculiaridades e as necessidades do trabalho no serviço público.

\section{Processo de trabalho no SUS}

Alguns formandos verificaram o serviço público com condições de trabalho inconsistentes: "muito precário em materiais (...), muito escasso material, em auxílio para o dentista" (E09), "não sei se eu consigo atender toda aquela demanda sozinha" (E06), e por isso: "não consegue sanar o que o paciente precisa" (E23), e "acaba não podendo oferecer o melhor [tratamento] para o seu paciente" (E08).

Em relação à percepção da existência de alta demanda de usuários no serviço público, retoma a ideia discutida na categoria anterior, sobre a baixa cobertura de assistência odontológica e uma implantação tardia da Política Nacional de Saúde Bucal, e por isso, histórico de demanda reprimida com necessidades odontológicas ao longo do tempo (Pucca-Junior et al., 2015). Apesar das melhorias na saúde bucal pública no Brasil, e grande expansão relacionados aos recursos físicos, humanos e infraestrutura, principalmente na Atenção Primária à Saúde e nos Centros de Especialidades Odontológicos nos últimos anos (Pucca-Junior et al., 2015), a falta de condições de trabalho e a burocracia do serviço público ainda se apresentam como justificativas para a dificuldade nas ações dos cirurgiões-dentistas (Bottan et al., 2014). No entanto, a falta de materiais ou de infraestrutura adequada para atendimento dos usuários também foi verificada no serviço privado, principalmente atrelado a franquias ou convênios, em estudo com recém-formados (Saliba et al., 2012).

Além disso, a rápida evolução da ciência odontológica e a expansão da tecnologia de ponta podem representar um alvo de insegurança para os futuros profissionais, ao se sentirem incapazes de resolver as demandas dos usuários frente à relativa baixa densidade tecnológica no SUS, ao acentuado viés burocrático e à sua baixa governabilidade. Deve-se ainda discutir que, no campo da saúde, uma nova tecnologia não implica necessariamente em melhor cuidado, e esta questão precisa ser melhor discutida nas faculdades de Odontologia. A maioria destas inovações de tecnologias duras, na verdade nem se tornam comercializáveis ou absorvidas pelo mercado, seja pela vasta experiência e habilidade técnica de procedimentos padrão-ouro, ou pelo alto custo e falta de capacitação para adequação das novas tecnologias pelos profissionais. A adesão de recursos para compra de tecnologia dura, mesmo em consultório particular, leva em consideração critérios como aplicabilidade, demanda e custo-benefício, aspectos ainda difíceis de serem enxergados por formandos em Odontologia (Albuha Al-Mussawi et al., 2016).

Alguns formandos ainda justificaram que: "'não tenho interesse no que é feito [procedimentos] no posto de saúde", (E08). Outros acreditam que: '’não acaba fazendo muita coisa (...), não fazia tratamento de canal(...), prótese que é uma coisa que eu gosto de fazer" (E20); precisa "mandar pro Centro de Especialidades" (E23).

Estes discursos apontam, de certa maneira, um entendimento equivocado e preconceituoso sobre a organização hierárquica do SUS e os seus níveis de atenção, atribuindo baixa importância aos serviços que são oferecidos no nível da atenção primária à saúde (APS). Ao considerar o trabalho na APS como uma prática reducionista ou de baixa relevância, os demais níveis de atenção presentes na Rede de Atenção à Saúde Bucal (RASB) podem tornar-se igualmente desinteressantes ou invisíveis enquanto campos profissionais em Odontologia, uma vez que a APS é o centro ordenador das Rede de Atenção à Saúde e que rotineiramente os estágios extramuros supervisionados na área da saúde ocorrem na atenção primária (Fae et al., 2017; Silveira et al., 2015).

\section{Perfil do usuário do SUS}

Todos os participantes do estudo expuseram que a escolha pelo trabalho no serviço público é também influenciada pelo perfil do usuário do SUS, sendo essa categoria, apontada concomitantemente como razão de interesse e 
desinteresse para o ingresso nessa modalidade de serviço.Entre os motivos de interesse surgiram os discursos: "gosto de trabalhar com esse tipo de pessoa" (E04), pois são "mais carentes, (...) de carinho mesmo" (E13) e por isso, precisam de habilidades profissionais que afirmaram ter: "eu consigo conversar, (...) tenho paciência" (E13).

Para entender o perfil atual do usuário do serviço público de saúde bucal no Brasil, deve-se entender os princípios do SUS e revisitar a história das políticas públicas de saúde bucal, marcadas pela exclusão social e atendimento mutilador (PuccaJunior et al., 2015). Embora tardia, a Política Nacional de Saúde Bucal, de 2004, segue a lógica dos princípios doutrinários do SUS, e apesar de ser norteada pela universalidade, as equipes de saúde bucal na atenção primária apresentam cobertura pouco maior de 50\% no Brasil (Brasil, 2018).

Ao ainda não conseguir garantir acesso universal, o princípio da equidade torna-se mais relevante, ou seja, necessidade de maior atenção àqueles indivíduos que precisam de maior cuidado nas unidades de saúde em nível primário para população historicamente desfavorecida dos serviços odontológico. Desta forma, apesar do SUS ser um serviço criado para todos, tem maior inserção entre a população de maior vulnerabilidade social e de saúde (Barros e Souza, 2016).

Sendo assim, o cirurgião-dentista inserido no serviço público precisa entender as especificidades da população adscrita, bem como, atentar-se à determinação social do processo saúde e doença. Para isso, o trabalho odontológico no campo da saúde pública deve ir além da aptidão técnica e individual, e ancorar-se no reconhecimento de individualidades humanas e de abordagens coletivas, por meio de práticas intersetoriais. Uma assistência clínica de cuidado centrado e ampliado, com projeto terapêutico singular, e ainda, uma abordagem coletiva, com medidas preventivas devem ser exaltadas (Brasil, 2017).

As características do usuário do serviço público foram também motivo de desinteresse nesse mercado para alguns formandos: "Os pacientes que a gente atende na saúde pública, (...) só vão quando estão com dor! (...) É só (...) abre, fecha buraco, tira a dor do paciente, ele fica sem dor e nunca mais volta! (...) A mentalidade do paciente [particular é] diferente, porque ele tá pagando (...), ele leva mais a sério, porque sai do bolso dele, (...) [o paciente da saúde pública] a gente não consegue mudar a cabeça dele, e eles tem uma cabeça muito fechada, (...) muito antiga'” (E19).

A baixa percepção de necessidades odontológicas ou o baixo valor atribuído por usuários à saúde bucal foram elementos evidentes para desestimular os formandos para a atuação no setor público. No entanto, essa característica secundária à saúde bucal faz parte do histórico de exclusão social vivenciado em um passado recente de acesso ao serviço de saúde bucal brasileiro, a qual acaba moldando comportamentos presentes (Fonseca et al., 2015). A saúde bucal é socialmente definida pelo que é visível em detrimento ao invisível (Bedos et al., 2009), e por isso, usuários buscam o serviço público, principalmente, em decorrência de problemas bucais mais urgentes, como dor e desconforto (Silva-Junior et al., 2017).

\section{Retorno social}

O aspecto social aparece em uma dimensão de poder "ajudar pessoas" (E12) ou de "um retorno (...) para sociedade; (...) eu [estudante] custo caro para o governo" (E21).Os formandos perceberam a execução do trabalho no serviço público como uma forma de devolutiva para a sociedade, inclusive pelo investimento custeado pelo Estado na sua formação profissional.

Os discursos deixaram evidente que o intuito dessa inserção no serviço público seria com uma relação trabalhista permanente, e não de voluntariado ou caridade. Esta percepção pode ser derivada em parte, por se tratar de amostra de uma instituição pública, onde a relação da contribuição na sociedade fica mais evidente, como também pelo perfil desses acadêmicos, cujo ingresso se deu por meio de ação afirmativa (sistema de cotas sociais por renda ou por raça/cor) implantada na IES de estudo.

Um estudo qualitativo com docentes mostrou na percepção de um professor de IES pública que acadêmicos mais carentes apresentavam maior preocupação de ações preventivas, enquanto um professor de IES privada identificou maior 
isolamento social entre acadêmicos que apresentavam um discurso com valor mais coletivo, ou seja, uma repressão do discurso (Finkler et al., 2018). Estes resultados podem sugerir um processo lento e gradual na diversidade do perfil acadêmico nos cursos de Odontologia, e por isso, uma perspectiva de muda valorização pelos acadêmicos nas disciplinas do eixo das ciências sociais e humanas, como nas disciplinas de Saúde Coletiva. Este fato pode refletir numa perspectiva de maior preocupação com os princípios de justiça, a solidariedade, a autonomia, entre outros (Finkler et al., 2018). No presente estudo, esse aspecto pode ser confirmado, ao verificar que os participantes que aderiram à política indutora PET-Saúde eram todos acadêmicos cotistas. Esta condição pode indicar outro aspecto importante de fixação de profissionais de saúde no mercado público.

\section{Considerações Finais}

Entre os formandos com interesse no mercado público a estabilidade profissional e financeira foi o principal motivador, seguido da percepção que o SUS seria um ambiente adequado para início de carreira ou lugar adequado para aprender-fazendo. As experiências vivenciadas dentro e fora do ambiente de formação foram consideradas como importantes tanto para interesse como para o desinteresse, uma vez que permitiram a identificação com o processo de trabalho e com o perfil do usuário do SUS. Além disso, o sentimento de retorno social pelo investimento recebido durante a formação profissional foi revelado. $\mathrm{O}$ desinteresse no mercado público odontológico esteve relacionado principalmente à percepção de uma carreira profissional defasada, condizente com pressupostos do modelo biomédico.

Os resultados do presente estudo evidenciaram que as experiências vivenciadas durante a formação acadêmica sugerem direcionar o perfil do mercado de trabalho desejado entre os formandos investigados. Nesse sentido, as vivências positivas ou negativas advindas de disciplinas e práticas educacionais que possibilitaram o conhecimento e experiência no serviço público, em especial os estágios no serviço de saúde público, ofertadas de forma obrigatória ou optativa, foram fatores condicionantes diretos ou indiretos para o interesse ou desinteresse no mercado de trabalho público em Odontologia. Ainda, a vivência do formando no processo de trabalho do SUS parece ser capaz de desenvolver uma visão mais crítica e realista sobre a profissão e sobre o setor público, direcionando-o a escolhas profissionais mais assertivas.

Nesse sentido, sugere-se a adesão e o reforço dos cursos de Odontologia, por meio principalmente de seus Projetos Político-Pedagógicos e Núcleos Docente Estruturantes, ao estímulo de vivências práticas e extraclínicas acadêmicas, à participação em políticas indutoras da formação em saúde pública e à ampliação da articulação ensino-serviço-comunidade em diferentes níveis. Alem disso, a realização de ciclos avaliativos e pesquisas científicas que possam acompanhar a implantação e efetivação das mudanças propostas nas DCN do curso de Odontologia.

\section{Referências}

Albuha Al-Mussawi, R. M. \& Farid, F. (2016). Computer-Based Technologies in Dentistry: Types and Applications. J. Dent., 13 (3), $215-222$.

Barbosa, K. G. N., Dias, J. N., Cavalvante, G. M. S., Nóbrega, L. M., Granville-Garcia, A. F. \& D’ávila, S. (2013). Formação e perspectiva do mercado de trabalho sob o olhar de alunos de odontologia. Pesq. Bras. Odontop. Clin. Integr., 13 (1): 89-94.

Bardin, L. (2016). Análise de conteúdo. Edições 70.

Cassol, T., Santos-Dullius, A. I. \& Ansuj, A. P. (2016). Perspectivas do acadêmico de odontologia de universidades do interior do Rio Grande do Sul-Brasil. Espacios, 37 (33), e10.

Barros, F. P. C. \& Sousa, M. F. (2016). Equidade: seus conceitos, significações e implicações para o SUS. Saúde Soc., 25 (1), 9-18.

Bedos, C., Levine, A., Brodeur, J. M. (2009). How People on Social Assistance Perceive, Experience, and Improve Oral Health. J. Dent. Res., 88 (7), 653-657.

Bottan, E. R., Vitoretti, A. J., Uriarte-Neto, M. (2014). Perfil profissional do cirurgião-dentista em atuação no serviço público: a visão de um grupo de cirurgiões-dentistas. Rev. Bras. Ciênc. Saúde (IMES), 12 (40), 42-47.

Brasil. Ministério da Saúde. Portal da Saúde. (2016). Informações de saúde (TABNET). http://migre.me/tshT7. 
Brasil. Portaria GM/MS no 2.436, de 21 de setembro de 2017. (2017). Aprova a Política Nacional de Atenção Básica, estabelecendo a revisão de diretrizes para a organização da Atenção Básica, no âmbito do Sistema Único de Saúde (SUS). Diário Oficial da União, 22 Set 2017.

Costa, S. M., Silveira, M. F., Durães, S. J. A., Abreu, M. H. N. G. \& Bonan, P. R. F. (2012). Perceptions of dental students regarding dentistry, the job market and the public healthcare system. Ciênc. Saúde Colet., 17 (5), 1285-1296.

Faé, J. M., Silva-Junior, M. F., Carvalho, R. B., Esposti, C. D. D. \& Pacheco, K. T. S. (2016). A integração ensino-serviço em Odontologia no Brasil. Rev. ABENO. 16 (3), 7-18.

Faé, J. M., Silva-Junior, M. F., Carvalho, R. B., Esposti, C. D. D. \& Pacheco, K. T. S. (2017). Perception of professional public service about teaching-service integration in Dentistry. Pesq. Bras. Odontop. Clin. Integr, 17 (1), e3204.

Farias-Santos, B. C. S. \& Noro, L. R. A. (2017). PET-Saúde como indutor da formação profissional para o Sistema Único de Saúde. Cienc. Saúde Colet., 22 (3), 997-1004.

Ferreira, N. P., Ferreira, A. P. \& Freire, M. C. M. (2013). Mercado de trabalho na Odontologia: contextualização e perspectivas. Rev. Odontol. UNESP, 42 (4), 304-309.

Finkler, M., Caetano, J. C. \& Ramos, F. R. S. (2014). Modelos, mercado e poder: elementos do currículo oculto que se revelam na formação em odontologia. Trab. Educ. Saúde., 12 (2), 343-361.

Fonseca, L. L. V., Nehmy, R. M. Q. \& Mota, J. A. C. (2015). O valor social dos dentes e o acesso aos serviços odontológicos. Ciênc. Saúde Colet., 20 (10), 3129-3138

Fontanella, V. B. J. B., Ricas, J., Turado, E. R. (2008). Amostragem por saturação em pesquisas qualitativas em saúde: contribuições teóricas. Cad. Saúde Pública, 24 (1), 17-27.

Gonçalves, C. L., Silva-Junior, M. F., Andrade, L. S., Miclos, P. V. \& Gomes, M. J. (2014). Odontologia hospitalar nos hospitais de grande porte da região metropolitana da Grande Vitória, Espírito Santo. Rev. Bras. Pesq. Saúde, 16 (1), 75-81.

Gondim, S. M. G. (2002). Perfil profissional e mercado de trabalho: relação com formação acadêmica pela perspectiva de estudantes universitários. Estud. Psicol., 7 (2), 299-309.

Kessler, M., Lima, S. B. S., Weiller, T. H., Lopes, L. F. D., Ferraz, L. \& Thumé, E. (2018). A longitudinalidade na Atenção Primária à Saúde: comparação entre modelos assistenciais. Rev. Bras. Enferm, 71 (3), 1063-1071.

Matos, M. S. \& Tenório, R. M. (2011). Expectativas de estudantes de odontologia sobre o campo de trabalho odontológico e o exercício profissional. Rev. Bras. Pesq. Saúde, 13 (4), 10-21.

Mendes, T. M. C., Oliveira, R. F. S., Mendonça, J. M. N., Medeiros-Junior, A. \& Castro, J. L. (2018). Planos de Cargos, Carreiras e Salários: perspectivas de profissionais de saúde do Centro-Oeste do Brasil. Saúde Debate, 42 (119), 849-861.

Morita, M. C., Haddad, A. E. \& Araújo, M. E. (2010). Perfil atual e tendências do cirurgião-dentista brasileiro. Maringá: Dental Press.

Peixoto, L. S., Gonçalves, L. C., Costa, T. D., Tavares, C. M. M., Cavalcanti, A. C. D. \& Cortez, E. A. (2013). Educación permanente, continuada y de servicio desvelando sus conceptos. Enferm. Global, 12 (29): 324-340.

Pucca Junior, G.A., Gabriel, M., Araujo, M. E. \& Almeida, F. C. (2015). Ten years of a National Oral Health Policy in Brazil: innovation, boldness, and numerous challenges. J. Dent. Res. 94 (10), 1333-1337.

Reibnitz Júnior, C., Caetano, J. C. \& Prado, M. L. (2009). A contribuição do trabalho odontológico na resolução de problemas de saúde da população: a concepção de alunos de Odontologia. Physis: Rev. Saúde Colet., 19 (1), 189-206.

Saliba, N. A., Moimaz, S. A. S., Prado, R. L. \& Garbin, C. A. S. (2012). Percepção do cirurgião-dentista sobre formação profissional e dificuldades de inserção no mercado de trabalho. Rev. Odontol. UNESP, 41(5), 297-304.

Silva-Junior, M. F., Souza, A. A. C., Batista, M. J. \& Sousa, M. L. R. (2017). Condição de saúde bucal e motivos para extração dentária entre uma população de adultos (20-64 anos). Ciênc. Saúde Colet., 22 (8), 2693-2702.

Silveira, J. L. G. C., \& Garcia, V. L. (2015). Mudança curricular em Odontologia: significados a partir dos sujeitos da aprendizagem. Interface Comum. Saúde Educ., 19 (52), 145-158.

Sousa, J. E., Maciel, L. K. B., Oliveira, C. A. S. \& Zocratto, K. B. F. (2017). Mercado de trabalho em Odontologia: perspectivas dos estudantes concluintes de faculdades privadas. Rev. ABENO, 17 (1), 74-86.

Souza, L. R. F., Silva, G. D., Oliveira, C. A. S. \& Zocratto, K. B. F. (2015). Mercado de trabalho: perspectivas dos alunos do curso de odontologia de uma faculdade particular de Belo Horizonte. Odontol, Clín.-Cient., 14 (3), 707-712. 